\title{
Artikel
}

\section{Artikel 4:74 BW: een erfrechtelijke bedrijfsopvolgingsfaciliteit}

\author{
Mr. J.L.D.J. Maasland*
}

\section{Inleiding}

Het is evident dat de legitieme portie sinds de invoering van het nieuwe erfrecht sterk aan kracht heeft ingeboet. ${ }^{1}$ Desalniettemin blijft de legitieme portie, ook nu deze verbintenisrechtelijk van aard is, een factor van betekenis wanneer de nalatenschap grotendeels bestaat uit een waardevol belang in een (familie)bedrijf. Wanneer er geen langstlevende partner is ${ }^{2}$ heeft het inroepen van de legitieme portie in een dergelijke situatie tot gevolg dat er na verloop van zes maanden na het overlijden ${ }^{3}$ een aanzienlijke geldsom betaalbaar moet worden gesteld aan de legitimaris. Indien de desbetreffende nalatenschap naast het belang in het familiebedrijf geen liquiditeiten van enige betekenis omvat, is het veelal noodzakelijk om het aan de legitimaris te betalen bedrag te onttrekken aan de onderneming. Zeker bij een kapitaalsintensieve onderneming kan dit een bedreiging vormen voor de continuiteit van de onderneming.

In deze bijdrage bespreek ik de mogelijkheden die het erfrecht geeft om het gesignaleerde probleem het hoofd te bieden. Ik ga daarbij ook in op de vraag in hoeverre de juridische structurering van de onderneming van

* Mr. J.L.D.J. Maasland is senior kandidaat-notaris bij Loyens \& Loeff N.V. te Amsterdam.

1. Zie bijvoorbeeld B.M.E.M. Schols, De legitieme portie driedimensionaal: abstract, concreet en fiscaal, in: Nieuw erfrecht in de praktijk. Een evaluatie (preadvies Koninklijke Notariële Beroepsorganisatie 2006), Den Haag: Sdu Uitgevers 2006, p. 95-171.

2. En dus geen uitgestelde opeisbaarheid van de legitieme portie ingevolge art. 4:81 lid 2, art. 4:82 dan wel art. 4:83 BW.

3. Art. 4:81 lid 1 BW invloed is op de toepasselijkheid van de erfrechtelijke faciliteiten op dit vlak.

\section{Legaat geldsom in termijnen}

Een manier om enerzijds de legitimaris het hare of het zijne te geven en anderzijds niet een al te zwaar beslag op de liquiditeitspositie van de onderneming te leggen is door aan de legitimaris een geldsom ter grootte van (ten minste) diens legitieme portie te legateren en daarbij te bepalen dat het legaat in termijnen opeisbaar is. Op deze manier kan het aan de legitimaris - in dit geval tevens legataris - te betalen bedrag worden gefinancierd uit de resultaten van de onderneming gedurende de (eerste) jaren na het overlijden van de erflater.

Een dergelijk legaat is evenwel in beginsel inferieur, waardoor de legitimaris het straffeloos zou kunnen verwerpen (art. 4:73 lid 1 onder c van het Burgerlijk Wetboek $(\mathrm{BW}))$. De wetgever heeft echter oog gehad voor de ondernemer ${ }^{4}$ door in artikel 4:74 BW als het ware een erfrechtelijke bedrijfsopvolgingsfaciliteit op te nemen. ${ }^{5}$ Lid 1 van dit artikel luidt als volgt:

'De contante waarde van een aan een legitimaris gemaakt legaat van een in termijnen te betalen geldsom komt ook bij verwerping in mindering van zijn legitieme portie, indien in de uiterste wil is vermeld

4. Van der Burght c.S., Parl. Gesch. Boek 4, Deventer: Kluwer 2002, p. 462.

5. Zie over deze regeling onder meer W. Burgerhart, Bedrijfsopvolging; erfrechtelijke en schenkingsrechtelijke aspecten, in: Bedrijfsopvolging. Civielrechtelijke en fiscaalrechtelijke aspecten (preadvies Koninklijke Notariële Beroepsorganisatie 2005), Den Haag: Sdu Uitgevers 2005, p. $404-408$ 
dat zonder deze beschikking de voortzetting van een beroep of bedrijf van de erflater in ernstige mate zou worden bemoeilijkt. Met een beroep of bedrijf van de erflater wordt gelijkgesteld een onderneming, gedreven door een naamloze vennootschap of besloten vennootschap met beperkte aansprakelijkheid waarvan de erflater bestuurder was en waarin deze alleen of met zijn medebestuurders de meerderheid der aandelen hield.'

De rechtvaardiging van de door artikel 4:74 BW gemaakte uitzondering op de hoofdregel dat de legitimaris zijn legitieme portie 'vrij en onbezwaard' dient te ontvangen, is gelegen in het wegnemen van belemmeringen in de bedrijfsopvolging. ${ }^{6}$ Het is voor de toepasselijkheid van artikel 4:74 BW niet vereist dat het legaat van een in termijnen te betalen geldsom ten laste komt van één of meer erfgenamen of legatarissen - tevens bedrijfsopvolgers - die eveneens legitimaris zijn. Ook indien een ander dan een legitimaris het beroep of het bedrijf voortzet, kan de bepaling toepassing vinden. ${ }^{7}$ Oorspronkelijk waren in het wetsvoorstel van artikel 4:74 lid $1 \mathrm{BW}$ de woorden 'ten laste van een of meer der overige legitimarissen' en 'door een of meer der overige legitimarissen' opgenomen, maar deze zijn bij de zesde nota van wijziging geschrapt. ${ }^{8}$

De faciliteit heeft betrekking op de contante waarde van het in termijnen opeisbare geldlegaat. Behoudens een eventuele zakelijke rentevergoeding over de nog niet opeisbare termijnen, zal deze contante waarde over het algemeen lager zijn dan het totaal van de nominale termijnen. De wet bepaalt niet hoe de contante waarde van het in termijnen te betalen geldlegaat dient te worden berekend. In de parlementaire geschiedenis is opgemerkt dat het legaat herrekend moet worden naar de contante waarde, door de termijnen te beschouwen als aflossing en rente, naar een 'redelijke rentevoet'.

Indien de contante waarde van het legaat van een in termijnen opeisbare geldsom lager is dan het nominale bedrag van de legitimaire vordering, dient het meerdere van de vordering van de legitimaris alsnog in beginsel na verloop van zes maanden na het overlijden te worden voldaan. ${ }^{10}$ Dit is een punt om rekening mee te houden bij het redigeren van het legaat aan de legitimaris van de in termijnen opeisbare geldsom. ${ }^{11}$ Daarnaast moet bij het redigeren van het testament de draagplicht van het legaat, in afwijking van artikel 4:117 lid 2 BW, worden verlegd naar de erfgenamen of legatarissen die de onderneming voortzetten. Voor zover het legaat ten laste komt

6. Mellema-Kranenburg, in: GS Erfrecht, art. 4:74 BW, aant. 2

7. Asser/Perrick 4 2017/327.

8. Van der Burght C.S., Parl. Gesch. Invoeringswet Boek 4, Deventer: Kluwer 2003, p. 1892

9. Van der Burght C.S., Parl. Gesch. Boek 4, p. 461. Zie ook B.C.M. Waaijer, in: M.J.A. van Mourik (red.), Handboek erfrecht, Deventer: Wolters Kluwer 2015, nr. X.13.

10. Behoudens gevallen van uitgestelde opeisbaarheid op grond van art. 4:81 lid 2, art. 4:82 dan wel art. 4:83 BW.

11. Zie ook Estate Tip Review 2008-30. van een niet-voortzetter, vindt artikel 4:74 BW namelijk geen toepassing. ${ }^{12}$

Voor toepassing van de faciliteit is vereist dat de grond ofwel beweegreden voor het legaat in termijnen in de uiterste wil is vermeld. ${ }^{13}$ In deze grond, zoals geduid door artikel 4:74 lid $1 \mathrm{BW}$, valt een tweetal elementen te onderscheiden, te weten: 'voortzetting van een beroep of bedrijf van de erflater' (juridische toets) en 'in ernstige mate worden bemoeilijkt' (economische toets).

De terminologie 'voortzetting van een beroep of bedrijf van de erflater' doet denken aan artikel 4:38 BW, onderdeel van Boek 4, titel 4, afdeling 2 BW, waarin de andere wettelijke rechten zijn opgenomen. Artikel 4:38 BW betreft eveneens een erfrechtelijke bedrijfsopvolgingsfaciliteit, die de bedrijfsopvolger de mogelijkheid biedt tegen betaling van een redelijke prijs de goederen die dienstbaar waren aan een door de erflater uitgeoefend beroep of bedrijf over te nemen van de erfgenamen van erflater.

In zijn dissertatie stelt Burgerhart dat voor de vraag of sprake is van de 'voortzetting van een beroep of bedrijf van de erflater' beslissend zal moeten zijn of de identiteit van de door de erflater gevoerde onderneming - beroep of bedrijf - bewaard blijft. Deze identiteit is de resultante van de door de erflater ontplooide ondernemende activiteiten. ${ }^{14}$ Volgens de minister ${ }^{15}$ kan een richtsnoer gevonden worden in de regeling voor de overgang van ondernemingen die in het kader van het arbeidsrecht in artikel 7:662 e.v. BW is opgenomen, en de daaromtrent bestaande literatuur en jurisprudentie.

Blijkens de parlementaire geschiedenis van artikel 4:38 $\mathrm{BW}$ is niet vereist dat het beroep of bedrijf door een erflater tot zijn dood is voortgezet. Zo kan de uitoefening van het bedrijf ten gevolge van ziekte reeds vóór zijn overlijden zijn opgeschort. Van voortzetting van erflaters beroep of bedrijf is evenwel geen sprake indien erflater de onderneming reeds lang geleden aan een derde heeft overgedragen. ${ }^{16}$ Mij lijkt dat hetzelfde geldt voor artikel 4:74 BW.

De Commissie Erfrecht van de Koninklijke Notariële Beroepsorganisatie (KNB) stelt dat voor de toepassing van artikel 4:74 BW vereist is dat de onderneming van de erflater tot diens nalatenschap behoort. ${ }^{17}$ Kennelijk wordt het in artikel 4:74 lid 1 BW opgenomen vereiste 'voortzetting van een beroep of bedrijf van de erflater' door de commissie uitgelegd als de 'voortzetting van een tot diens overlijden door de erflater uitgeoefend beroep of bedrijf. Op basis hiervan concludeert de commissie dat

12. Klaassen/Luijten \& Meijer II, Erfrecht 2008/569.

13. Klaassen/Luijten \& Meijer II, Erfrecht 2008/568.

14. W. Burgerhart, Waarde en erfrecht. Beschouwingen over de waarde van een onderneming in het erfrecht en enige verwante wetten (diss. Nijmegen), Deventer: Kluwer 2008, p. 436-438.

15. Van der Burght c.s., Parl. Gesch. Invoeringswet Boek 4, p. 1762

16. Van der Burght C.S., Parl. Gesch. Invoeringswet Boek 4, p. 1761.

17. Concept-Eindverslag Commissie Erfrecht KNB inzake Boek 4 BW (I), WPNR 2010/6866, p. 889. 
de bedrijfsopvolger niet wordt beschermd ingeval de erflater zijn onderneming reeds bij leven heeft overgedragen, maar deze nog wel financiert om de voortzetting mogelijk te maken. In dergelijke situaties kan de nalatenschap een vordering op de opvolger bevatten, of cumulatief preferente aandelen die zijn uitgegeven in het kader van de overname van een vennootschap waarin de onderneming wordt uitgeoefend. De commissie geeft, mede aangezien in dergelijke situaties de bedrijfsopvolgingsregeling in de Successiewet 1956, onder strikte voorwaarden, wel kan worden toegepast, in overweging om artikel 4:74 BW daarop eveneens van toepassing te verklaren.

De vraag of zonder uitbetaling in termijnen de voortzetting van erflaters beroep of bedrijf in ernstige mate wordt bemoeilijkt, dient blijkens de parlementaire geschiedenis $^{18}$ te worden beoordeeld naar het tijdstip van het openvallen van de nalatenschap.

\section{Procedurele aspecten}

Indien de in het testament vermelde grond voor het legaat in termijnen naar de mening van de legitimaris onjuist is, kan deze binnen drie maanden na het overlijden van de erflater verklaren dat hij betaling van de contante waarde ineens verlangt (art. 4:74 lid 2 BW). Op grond van bijzondere omstandigheden kan de termijn van drie maanden door de kantonrechter worden verlengd, zelfs nadat de termijn reeds was verlopen (art. 4:77 BW). In de Handleiding erfrechtprocedures kantonrechter ${ }^{19}$ is als aanbeveling aan de kantonrechters opgenomen om in dit verband de eerste keer ruimhartig te werk te gaan, bijvoorbeeld indien de legitimaris nog niet het noodzakelijke inzicht heeft kunnen krijgen.

De bewijslast voor de juistheid van de grond voor het legaat van een in termijnen opeisbaar geldlegaat rust op degene die de juistheid van de grond staande houdt, aldus artikel 4:74 lid 2 BW. Dit zal doorgaans de bedrijfsopvolger zijn, die de onderneming van erflater heeft voortgezet, dan wel de executeur, die belast is met de afgifte van het legaat. Bij de beoordeling van een betwisting in rechte van de juistheid van de in artikel 4:74 lid 1 BW bedoelde grond zal de rechtbank een afweging moeten maken tussen de belangen van de bedrijfsopvolger enerzijds en die van de legitimaris anderzijds.

Ook aan de legitimaris die eerst het aan hem gemaakte legaat verwerpt en vervolgens een beroep doet op zijn legitieme portie, kan de regeling van artikel 4:74 lid 1 BW worden tegengeworpen. Wanneer de legitimaris dan ook aan de juistheid van de grond twijfelt, moet hij niet verwerpen, maar op basis van artikel 4:74 lid 2 BW

18. Van der Burght c.s., Parl. Gesch. Vaststellingswet Boek 4, Deventer: Kluwer 2003, p. 461

19. Vastgesteld door het Landelijk Overleg Vakinhoud Civiel en Kanton \& Toezicht (LOVCK\&T), versie 7.0 de dato 8 oktober 2018. verklaren dat hij de contante waarde van de hem vermaakte geldsom wenst te ontvangen. ${ }^{20}$

Indien de opgegeven grond voor het in termijnen opeisbare legaat weliswaar juist is, maar in het concrete geval een snellere afbetaling mogelijk is, zonder dat de continuiteit van de onderneming hierdoor in gevaar komt, kan de rechter de verbintenis uit het legaat in deze zin wijzigen (art. 4:74 lid 2 BW). De legitimaris dient zich hiertoe te wenden tot de rechtbank. ${ }^{21}$ Tegen een vonnis van de rechtbank in dit verband staat hoger beroep open.

Artikel 4:74 BW stelt niet als voorwaarde dat de onderneming van de erflater daadwerkelijk wordt voortgezet. $^{22}$ Wel geldt dat indien op enig moment na het overlijden van de erflater de noodzaak voor de betaling in termijnen van het legaat wegvalt, de legataris de rechter op grond van artikel 4:123 BW kan verzoeken de verbintenissen uit het legaat te wijzigen. De rechter dient vervolgens te oordelen of sprake is van een omstandigheid die van zodanige aard is, dat de partij die tot afgifte van het legaat gehouden is, naar maatstaven van redelijkheid en billijkheid ongewijzigde instandhouding van die verbintenissen niet mag verwachten. Een voorbeeld waarin hiervan mijns inziens sprake is, is het geval waarin de onderneming na het overlijden van erflater wordt verkocht, waardoor voldoende liquide middelen ter beschikking komen om de vordering van de legataris ineens te voldoen.

Bij toepassing van de faciliteit van artikel 4:74 BW hoeft de bedrijfsopvolger geen zekerheid te stellen voor de voldoening van zijn verplichtingen ten opzichte van de legataris, tenzij de kantonrechter dit op verzoek van de legitimaris zou bevelen. De kantonrechter stelt hierbij het bedrag en de aard (persoonlijk of goederenrechtelijk) van de zekerheid vast. Ook stelt de kantonrechter de termijn waarbinnen zekerheid moet worden gesteld. Indien deze termijn wordt overschreden, komt het in termijnen opeisbare geldlegaat alsnog niet in mindering van de legitieme portie indien de legitimaris het legaat verwerpt (art. 4:73 BW). Deze verwerping dient binnen drie maanden na het verstrijken van de door de kantonrechter gestelde termijn voor het stellen van zekerheid plaats te vinden. ${ }^{23}$

\section{Structurering van de onderneming}

Uit de wettekst van artikel 4:74 lid $1 \mathrm{BW}$ volgt dat de faciliteit ook kan worden benut indien de erflater zijn

20. Klaassen/Luijten \& Meijer II, Erfrecht 2008/569

21. En dus niet de kantonrechter; zie het commentaar in de Handleiding erfrechtprocedures kantonrechter bij art. 4:74 lid 3 BW. Zie hierover ook Estate Tip Review 2018-07.

22. Burgerhart, Waarde en erfrecht, p. 453.

23. Waaijer, Handboek erfrecht, nr. X.13 en Asser/Perrick 4 2017/327. 
onderneming middels een naamloze vennootschap of een besloten vennootschap met beperkte aansprakelijkheid dreef. In dat geval is vereist dat erflater bestuurder was van de desbetreffende vennootschap. De tweede voorwaarde is dat erflater, alleen of met zijn medebestuurders, de meerderheid van de aandelen in de vennootschap hield. Deze vereenzelvigingsregel is pas in een laat stadium van de totstandkoming van het nieuwe Boek 4 BW, te weten in het voorstel voor de Bezemwet, aan artikel 4:74 lid $1 \mathrm{BW}$ toegevoegd. ${ }^{24}$

De wet spreekt over 'aandelen'. Een voor de praktijk belangrijke vraag is of certificaten van aandelen hieronder mede begrepen zijn. Bij veel familiebedrijven zijn de aandelen in de centrale houdstervennootschap immers gecertificeerd, om de zeggenschap over en het economisch belang bij de onderneming te scheiden.

De vergelijking dringt zich op met artikel 4:38 lid 2 BW, waar eveneens wordt gesproken over 'aandelen in een naamloze vennootschap of besloten vennootschap met beperkte aansprakelijkheid waarvan de erflater bestuurder was en waarin deze alleen of met zijn medebestuurders de meerderheid der aandelen hield'. Dezelfde zinsnede is ook opgenomen in artikel 1:88 lid $5 \mathrm{BW}$, dat (kort gezegd) een uitzondering op het wettelijke toestemmingsvereiste bevat voor handelingen die in de normale uitoefening van het bedrijf van een vennootschap zijn verricht.

Blijkens de nota naar aanleiding van het verslag van de Bezemwet ${ }^{25}$ vallen certificaten van aandelen niet onder de in artikel 4:74 BW opgenomen vereenzelvigingsbepaling. ${ }^{26}$ Ook bij de vereenzelvigingsregels van artikel 4:38 lid $2^{27}$ en 1:88 lid $5 \mathrm{BW}^{28}$ wordt een formeel vereenzelvigingscriterium gehanteerd, dat uitsluitend geldt voor aandelen.

Bedacht zou kunnen worden om de aandelen in de vennootschap waarin de onderneming wordt gedreven te certificeren en de certificaten van aandelen vervolgens in te brengen in een houdstervennootschap, waarvan de aandelen door de erflater worden gehouden. In dat geval behoren immers de aandelen tot de nalatenschap. In de literatuur is volop gediscussieerd over de vraag of middellijk aandeelhouderschap, dat wil zeggen een onderneming die door een holding wordt gehouden, kwalificeert voor toepassing van de bedoelde vereenzelvigingsregels. De rode draad is dat dit zonder nadere toelichting of aanvulling niet het geval is.

Zowel de Commissie Erfrecht van de $\mathrm{KNB}^{29}$ als Burgerhart $^{30}$ heeft gepleit voor een materieel vereenzelvigingscriterium, dat zowel certificaten van aandelen als

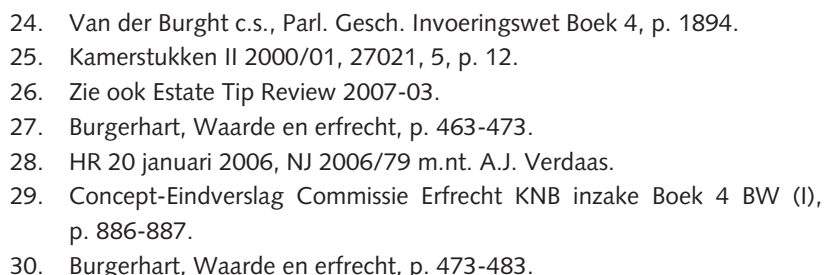

aandelen in een holding omvat. Hiermee zou recht worden gedaan aan het doel van artikel 4:74 BW, te weten het faciliteren van de erfrechtelijke bedrijfsopvolging. De context van het vereenzelvigingscriterium in de artikelen 4:38 en 4:74 BW (faciliteren van de erfrechtelijke bedrijfsopvolging) is wezenlijk anders dan die van artikel 1:88 BW (gezinsbeschermende bepaling). Dit rechtvaardigt mijns inziens een andere invulling van het erfrechtelijke vereenzelvigingscriterium dan het in artikel 1:88 lid 5 BW opgenomen criterium, hoewel de beide criteria tekstueel identiek zijn.

Artikel 4:36 BW (de som ineens als billijke vergoeding voor in de huishouding of de onderneming van de erflater verrichte arbeid waarvoor geen passende beloning is ontvangen, ofwel het 'salaire differé') bevat geen vereenzelvigingsbepaling. Deze wettelijke bepaling spreekt slechts over een 'door de erflater uitgeoefend beroep of bedrijf'. In een recent arrest over deze regeling heeft het Gerechtshof Amsterdam ${ }^{31}$ geoordeeld:

'Naar het oordeel van het hof vormt de "billijkheidsgedachte" van artikel 4:36 BW - in aanmerking genomen hetgeen het hof hiervoor heeft overwogen onvoldoende grond om in afwijking van de tekst en de wetssystematiek de regeling toe te passen als de onbezoldigde arbeid is verricht voor de vennootschap [DJM: waarvan de erflater aandeelhouder was] en om in zijn algemeenheid vereenzelviging aan te nemen.'

\section{Algemene erfrechtelijke betalingsregeling}

Ook indien een beroep op artikel 4:74 BW, als lex specialis, geen stand zou houden, staat voor de schuldenaar van de voldoening van een schuld uit hoofde van ofwel een legaat aan de legitimaris, ofwel de legitimaire vordering zelf de mogelijkheid open een beroep te doen op de algemene erfrechtelijke betalingsregeling, opgenomen in artikel 4:5 BW. Dit artikel bepaalt dat indien sprake is van gewichtige redenen, de rechtbank op verzoek van de schuldenaar kan bepalen dat een geldsom die krachtens Boek 4 BW is verschuldigd, zoals de legitieme portie, ${ }^{32}$ eerst na verloop van zekere tijd, hetzij ineens, hetzij in termijnen, behoeft te worden voldaan. Artikel 4:125 lid 4 BW verklaart artikel 4:5 BW van overeenkomstige toepassing op legaten van een geldsom, die immers hun grondslag niet rechtstreeks in de wet vinden.

Blijkens de parlementaire geschiedenis ${ }^{33}$ is ook de algemene erfrechtelijke betalingsregeling van artikel 4:5 BW in het bijzonder met het oog op de vererving van ondernemingen opgenomen. De minister heeft in dit verband gesteld:

31. Hof Amsterdam 12 februari 2019, ECLI:NL:GHAMS:2019:369.

32. Asser/Perrick 4 2017/337a.

33. Van der Burght c.s., Parl. Gesch. Invoeringswet Boek 4, p. 1182. 
'Het artikel bevat de eerste van de reeks bepalingen die in het ontwerp in het bijzonder met het oog op de vererving van bedrijven zijn opgenomen.

Uit het erfrecht kunnen geldschulden ontstaan. Te denken valt aan de vergoeding wegens overbedeling of wegens overneming van een bedrijf, aan de legitimaire vordering en aan de rechten op sommen ineens. Deze geldbedragen zijn in beginsel terstond of op korte termijn opeisbaar, doch het kan voor de schuldenaar zeer bezwaarlijk zijn zo spoedig volledig aan zijn verplichtingen te moeten voldoen. In het bijzonder is dat het geval, indien de rechtelijke schuld uit de opbrengsten van een beroep of bedrijf moet worden voldaan. Tegeldemaking van beroeps- of bedrijfsgoederen op korte termijn betekent voor de schuldenaar een zware last, maar zal ook voor de schuldeiser vaak onvoordelig zijn. (...) Ter vervanging van bijzondere bepalingen in Boek 4 wordt nu aan het slot van de algemene bepalingen in het erfrecht een regeling opgenomen, waarvan de tekst in hoofdzaak is geinspireerd door artikel 1:145 lid 2 BW.'

Voor de volledigheid zij opgemerkt dat artikel 4:5 BW uiteindelijk niet in de plaats van, maar naast artikel 4:74 $\mathrm{BW}$ in de wet is opgenomen.

Bij de beoordeling van het verzoek let de rechtbank op de belangen van beide partijen, aldus artikel 4:5 lid 1 BW. Zoals ook blijkt uit de hiervoor angehaalde parlementaire geschiedenis, kan de continuiteit van de onderneming die wordt voortgezet door de schuldenaar, respectievelijk schuldenaren van het legaat aan de legitimaris dan wel de legitimaire vordering gelden als een gewichtige reden in de zin van artikel 4:5 lid $1 \mathrm{BW}$.

De rechtbank kan aan de inwilliging van een verzoek tot het treffen van een betalingsregeling voorwaarden verbinden, bijvoorbeeld dat zakelijke of persoonlijke zekerheid voor de voldoening van de vordering van de legitimaris wordt gesteld. Bij het vaststellen van de betalingsregeling kan de rechtbank voorts bepalen dat de vordering van de legitimaris die in termijnen zal worden voldaan, wordt vermeerderd met een in de beschikking te bepalen rente. Dit geldt mijns inziens ook indien de legitimaire vordering op grond van artikel 4:84 BW renteloos is, ingeval de wettelijke rente minder dan zes procent bedraagt.

Een door de rechtbank opgelegde betalingsregeling kan nadien, op verzoek van een van de partijen, op grond van onvoorziene omstandigheden worden gewijzigd door diezelfde rechtbank (art. 4:5 lid 2 BW).

\section{Conclusie}

De wetgever heeft oog gehad voor het belang van de continuiiteit van familiebedrijven waarvan de eigendom door vererving overgaat naar de volgende generatie.
Door wettelijk te faciliteren dat de legitimaris het zijne of het hare krijgt zonder dat dit een te zwaar beslag legt op de liquiditeitspositie van de onderneming, is mijns inziens een afgewogen regeling getroffen. Door het feit dat de regeling te veel geënt is op een onderneming die rechtstreeks door de erflater dan wel via een eenvoudige vennootschapsstructuur wordt gedreven, is de praktische toepasbaarheid van de regeling echter (te) beperkt. Een keuze voor een materieel vereenzelvigingscriterium in plaats van het thans geldende formele vereenzelvigingscriterium zou dit bezwaar weg kunnen nemen. 